\title{
Role of morphological factors of pigeonpea in imparting resistance to spotted pod borer, Maruca vitrata Geyer (Lepidoptera: Crambidae)
}

\author{
Wasihun Yaregal Wubneh ${ }^{1}$ and Gaurav Kumar Taggar $^{2 *}$ \\ ${ }^{1}$ Department of Entomology, Punjab Agricultural University, Ludhiana-141 004 (Punjab), INDIA \\ ${ }^{2}$ Department of Plant Breeding \& Genetics, Punjab Agricultural University, Ludhiana- 141004 (Punjab), INDIA \\ *Corresponding author. E-mail: gauravtaggar@ pau.edu
}

Received: June 1, 2015; Revised received: November 2, 2015; Accepted: February 16, 2016

\begin{abstract}
Morphological characters of eleven test genotypes of pigeonpea, such as growth habit, pubescence of pods and leaves, pod angle and pod wall thickness were studied in order to work out the relationship of these traits vis-à-vis resistance/susceptibility to Maruca vitrata. It was observed that genotype AL 1747 possessed significantly highest trichome density on leaves and pods (177.33 and 43.33 trichomes $/ 4.6 \mathrm{~cm} 2$, respectively), whereas MN 1 possessed lowest trichome density (47.33 and 7.66 trichomes $/ 4.6 \mathrm{~cm}^{2}$, respectively). Trichome length on leaves and pods was significantly highest in AL 1747 (66.26 and $180.83 \mu \mathrm{m}$, respectively) and lowest in MN 1 (33.53 and 43.25 $\mu \mathrm{m}$, respectively). Genotype AL 1747 recorded significantly highest pod angle $\left(65^{\circ}\right)$, whereas $\mathrm{MN} 1$ recorded lowest pod angle $\left(18.66^{\circ}\right)$. There was significant negative correlation between trichome density on leaves and pods with larval weight gain $(r=-0.71$ and -0.69 , respectively) as well as with per cent pod damage $(r=-0.75$ and -0.75 , respectively) and between trichome length on leaves and pods with larval weight gain $(r=-0.81$ and -0.81 , respectively) as well as with per cent pod damage ( $r=-0.87$ and -0.87 , respectively). Pod angle was found to be significantly negatively correlated with both larval weight gain and per cent pod damage. Thus, early maturing pigeonpea genotypes with indeterminate growth habit, higher leaf and pod pubescence with wider pod angles should be preferred for breeding $M$. vitrata tolerant lines.
\end{abstract}

Keywords: Cajanus cajan, Maruca vitrata, Morphological factors, Pigeonpea, Pod damage, Trichomes

\section{INTRODUCTION}

Pigeonpea, [Cajanus cajan (L) Millsp] is an important grain legume in India and is grown in $3.5 \mathrm{~m}$ ha with an annual production of $2.4 \mathrm{mt}$ (FAO, 2005). More than 250 species of insects have been found feeding on pigeonpea. Among these spotted pod borer, Maruca vitrata (Geyer) derives its pre-eminent importance as a pest of tropical grain legumes from its extremely wide geographical distribution, extensive host range and its ability to infest the young growing plant tips, stems, flower buds, flowers, pods and seeds (Ranga Rao et al., 2007). With the introduction of short-duration pigeonpeas, $M$. vitrata has emerged as a major pest on this crop (Sharma and Franzmann, 2000). The pest is able to establish on the crop early. Its larvae damage the leaves by rolling and webbing, and feed inside the rolled leaves. At the flowering and pod formation stages, larvae feed on flowers, buds, and pods by webbing them. This typical feeding habit protects the larvae from natural enemies and other adverse factors, including chemicals (Sharma and Franzmann, 2000). Being a serious insect pest of early pigeonpea, yield losses due to $M$. vitrata in pigeonpea ranged up to 100 per cent and therefore, the development of resistant cultivars and germplasm is one of the best means for controlling this insect (Saxena et al., 2002).

Various biophysical characters of the plants like trichomes on stems, leaves, pods and their length and density, pod length, pod width, pod wall thickness, number of pods / clusters and angle between the pods play an important role by providing resistance to the plants against $M$. vitrata (Halder et al., 2006). Types of trichomes and their orientation, density and length have been found to influence host plant resistance/ susceptibility to insect pests (Valverde et al., 2001; Aruna et al., 2005; Sharma et al., 2009). Trichomes and trichome exudates on the pod wall surface play an important role in the ovipositional behavior and host selection process of insect herbivores (Bernays et al., 2000). Trichomes have been widely exploited as an insect defense mechanism in a number of crop plants including soybean (Lam and Pedigo, 2001), Arabidopsis (Karkkainen and Agren, 2002) and tomato (Simmons et al., 2004; Simmons and Geoff, 2004). Mortality of arthropod pests resulting from glandular trichomes has been hypothesized to be a result of physical entrapment (Muigai et al., 2002) as opposed to the toxic effects of compounds produced by the trichomes (Kennedy, 2003). The morphological factors may, therefore provide a potential resistance mechanism against $M$. vitrata in pigeonpea. The present 
study was undertaken to determine the role of morphological traits of early maturing pigeonpea genotypes associated with resistance to $M$. vitrata.

\section{MATERIALS AND METHODS}

To elucidate the role of various plant characteristics in imparting resistance/susceptibility to $M$. vitrata in pigeonpea test genotypes, studies were conducted in Pulses Entomology Laboratory, Department of Plant Breeding \& Genetics and Electron Microscopy \& Nanoscience (EMN) Laboratory, College of Agriculture, Punjab Agricultural University, Ludhiana. Studies on the biophysical traits of 11 pigeonpea test genotypes were undertaken by recording the observations on leaf and pod characteristics of each genotype.

On the basis of branching and flowering pattern, pigeonpea test genotypes were grouped as determinate (inflorescence bunched/clustered together) and indeterminate (inflorescence spreading/non-clustered). Observations on growth habit of test genotypes were recorded visually at 50 per cent flowering stage from three fully-formed trifoliate leaves and green pods of each test genotype per replication and imaged using scanning electron microscope (SEM) as per standard protocol (Bozzola and Russell, 1999). Imaging and counting was performed from three regions of single leaflet per genotype and observations were recorded from the electron micrographs of individual test genotypes. For measuring the trichome angle, a straight line was made parallel to the leaf base connecting the base of the trichome. Another line extending from the tip of the trichome to the base of the trichome was made using a scale. The angle between the two lines was measured using a protractor and expressed in degrees for each individual trichome. Observations were recorded by taking five hand cut cross-sections of green pods of test genotypes and the thickness of the outer peel portion (epidermis and underlying tissues) of these sections were measured under a compound microscope using stage and ocular micrometer. Angle between the two adjacent pods on the same petiole was measured by using a protractor and expressed in degrees.

Standard protocol for imaging leaf and pod samples under SEM: The leaf pubescence parameters viz., trichome density and trichome length were analyzed and imaged under Scanning Electron Microscope (SEM) at the Electron Microscopy and Nanoscience (EMN) Laboratory, College of Agriculture, Punjab Agricultural University, Ludhiana as per standard protocol given by Bozzola and Russell (1999). Fresh leaves of each test genotype were collected and immediately immersed in individual vials containing 2.5 per cent glutaraldehyde solution for primary fixation and kept overnight at a temperature of $4^{\circ} \mathrm{C}$. The leaf specimens were then washed thrice with distilled water. For secondary fixation, the specimens were immersed in 4 per cent osmium tetraoxide solution for a period of 2-4 hrs at $4^{\circ} \mathrm{C}$. After post-fixation, the specimens were again washed thrice (each washing of 5-10 min duration) using distilled water.

Dehydration of the specimen discs was performed using different grades of ethanol $(25,50,70,95$ and 100\%) each for a period of 20 minutes whereas the final dehydration (with $100 \%$ ethanol) was performed for 30 minutes. The specimens were dried to critical point in $\mathrm{CO}_{2}$ at $5^{\circ} \mathrm{C}$ and mounted on aluminium stub using double-sided carbon tape. Each specimen leaf disc was mounted with its lower surface up allowing the lower epidermal surfaces of each leaf to be examined. The mounted leaf specimens were sputter-coated with a thin layer of gold using an automated sputter coater. Finally, the specimens were examined and imaged using Hitachi S-3400N Scanning Electron Microscope operated at an accelerating voltage of $15 \mathrm{kV}$ using secondary electron detector. Similar procedure was followed for imaging the samples of pods of different genotypes of pigeonpea.

Statistical analysis: Data on the morphological plant characters were analyzed using ANOVA to test the significance of difference among genotypes using completely randomized design (CRD). Correlation coefficients for morphological plant characters with larval weight gain and per cent pod damage were also worked out.

\section{RESULTS AND DISSCUSSION}

Data pertaining to trichome density on leaves of different test genotypes of pigeonpea varied from 47.33-177.33 per $4.6 \mathrm{~cm}^{2}$ (Table 1). The leaf trichome density was significantly lowest in MN 1 (47.33 trichomes per $\left.4.6 \mathrm{~cm}^{2}\right)$ followed by ICPL $20340(55.00$ per $4.6 \mathrm{~cm}^{2}$ ) and AL 15 (59.66 per $\left.4.6 \mathrm{~cm}^{2}\right)$, while it was significantly highest in AL 1747 (177.33 trichomes per $4.6 \mathrm{~cm}^{2}$ ). The trichome density on the leaves of remaining test genotypes, viz. ICPL 98003, AL 1790, AL 201, AL 1770, AL 1735, AL 1495 and PAU 881 was 96.66, 94.66, 92.66, 88.00, 87.33, 85.33 and 82.33 trichomes per $4.6 \mathrm{~cm}^{2}$, respectively. The variation in the trichome density on the leaves of $\mathrm{AL}$ 1747 and MN 1 has also been depicted in Plate 1.

As far as trichome density on pods was concerned, it varied from 7.66-43.33 trichomes per $4.6 \mathrm{~cm}^{2}$ and differed significantly among various test genotypes of pigeonpea. Pods of genotype MN 1 were least pubescent (7.66 trichomes per $4.6 \mathrm{~cm}^{2}$ ), followed by AL $15(9.66$ trichomes per $\left.4.6 \mathrm{~cm}^{2}\right)$ and ICPL $20340(11.00$ trichomes per $4.6 \mathrm{~cm}^{2}$ ). However, pods of test genotype AL 1747 were highly pubescent with a trichome density of 43.33 per $4.6 \mathrm{~cm}^{2}$. The trichome density on the pods of remaining test genotypes, viz. AL 1770, ICPL 98003, AL 1790, AL 1735, AL 201, AL 1495 and PAU 881 was $34.33,25.66,25.33,19.66,17.66,16.33$ and 16.00 trichomes per $4.6 \mathrm{~cm}^{2}$, respectively. The variation in the trichome density on the pods of $\mathrm{AL}$ 1747 and MN 1 has also been depicted in Plate 2. 
Wasihun Yaregal Wubneh and Gaurav Kumar Taggar et al. / J. Appl. \& Nat. Sci. 8 (1): 218 - 224 (2016)

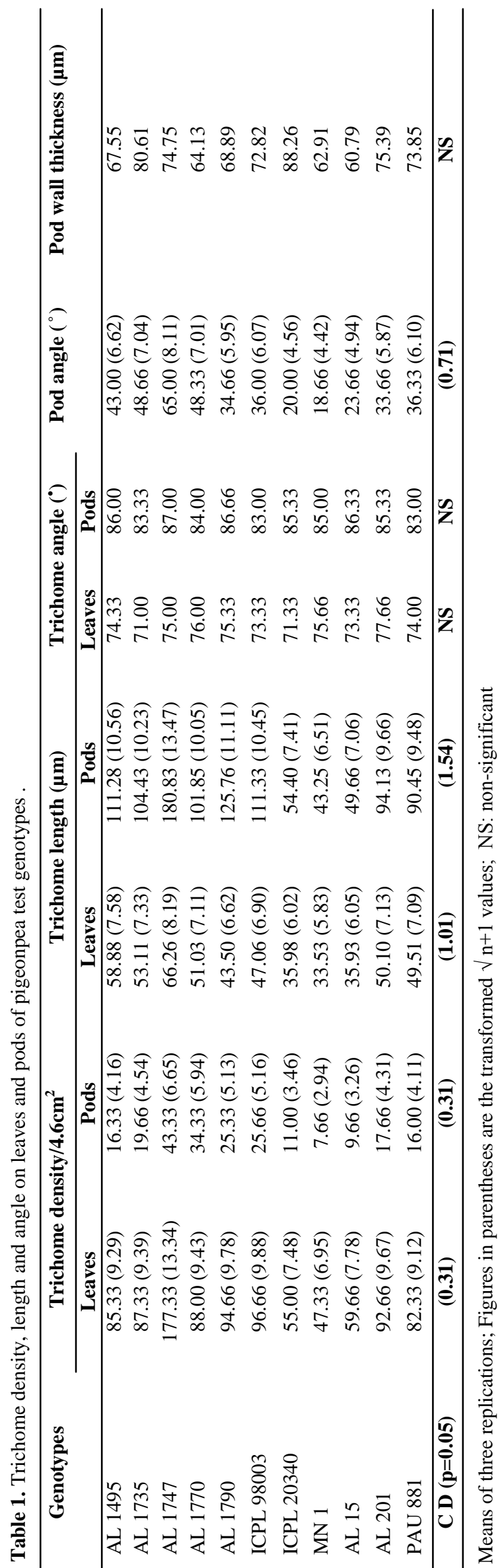

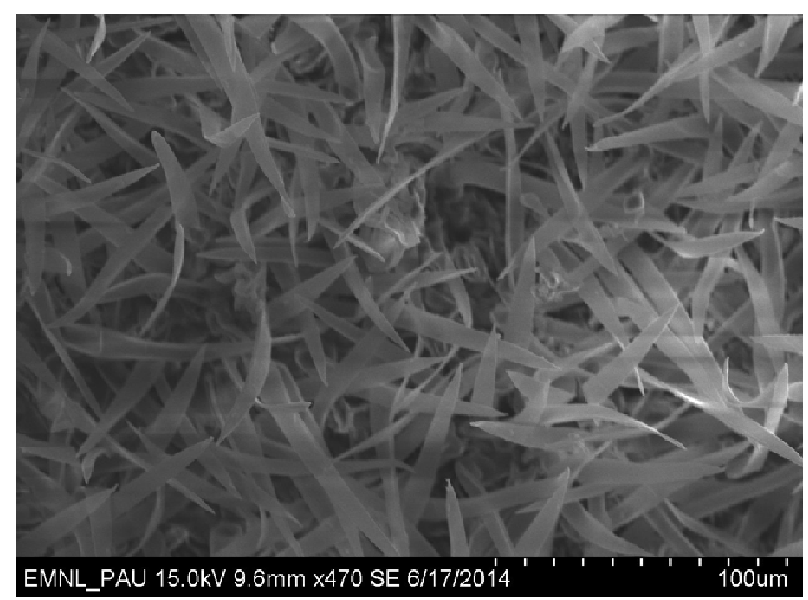

a. Resistant genotype - AL 1747

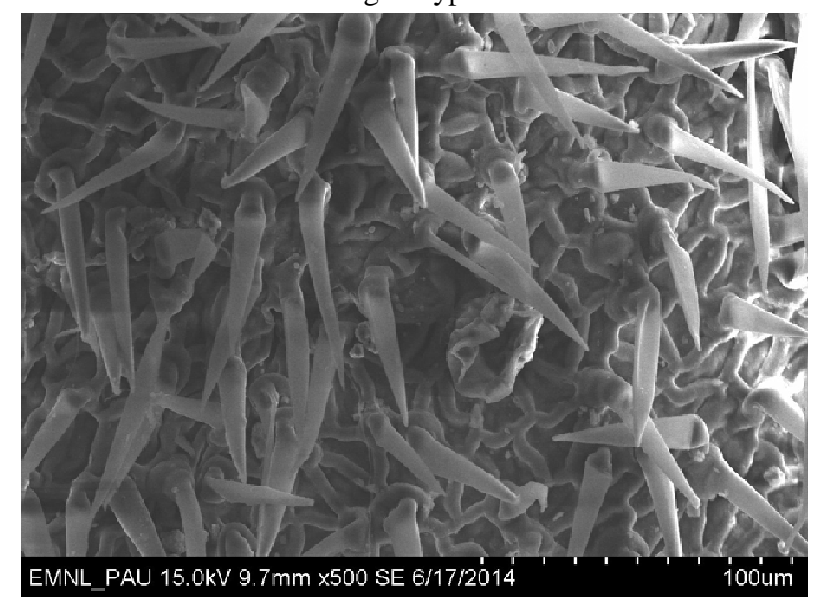

b. Susceptible genotype - MN 1

Plate 1. Scanning electron micrographs of the leaf surfaces of resistant and susceptible pigeonpea genotypes $(a-b)$ showing trichome density $(100 \mu \mathrm{m}$ corresponds to $6.5 \mathrm{~cm})$.

Trichome length on leaves of different test genotypes of pigeonpea varied from 33.53-66.26 $\mu \mathrm{m}$ (Table 1). The trichome length on leaves was significantly lowest in MN $1(33.53 \mu \mathrm{m})$ followed by ICPL 20340 (35.98 $\mu \mathrm{m})$ and $\mathrm{AL} 15(35.93 \mu \mathrm{m})$, while it was highest on AL $1747(66.26 \mu \mathrm{m})$. The trichome length on the leaves in the other test genotypes viz., AL 1495, AL 1735, AL 201, AL 1770, PAU 881, ICPL 98003 and AL 1790 was 58.88, 53.11, 50.10, 51.03, 49.51, 47.06 and $43.50 \mu \mathrm{m}$, respectively. As far as trichome length on pods was concerned, it varied from 43.25-180.83 $\mu \mathrm{m}$ among various test genotypes of pigeonpea. The length of trichomes on pods was significantly shortest in genotype $\mathrm{MN} 1(43.25 \mu \mathrm{m})$ followed by $\mathrm{AL} 15$ $(49.66 \mu \mathrm{m})$ and ICPL $20340(54.40 \mu \mathrm{m})$, while it was longest in AL $1747(180.83 \mu \mathrm{m})$. However, test geontypes, viz. AL 1790, ICPL 98003, AL 1495, AL 1735, AL 1770, AL 201 and PAU 881 recorded $125.76,111.33,111.28,104.43,101.85,94.13$ and $90.45 \mu \mathrm{m}$, respectively. The variation in the trichome length on the pods of AL 1747 and MN 1 has also been depicted in Plate 3.

The trichome angle on leaves and pods of different test 


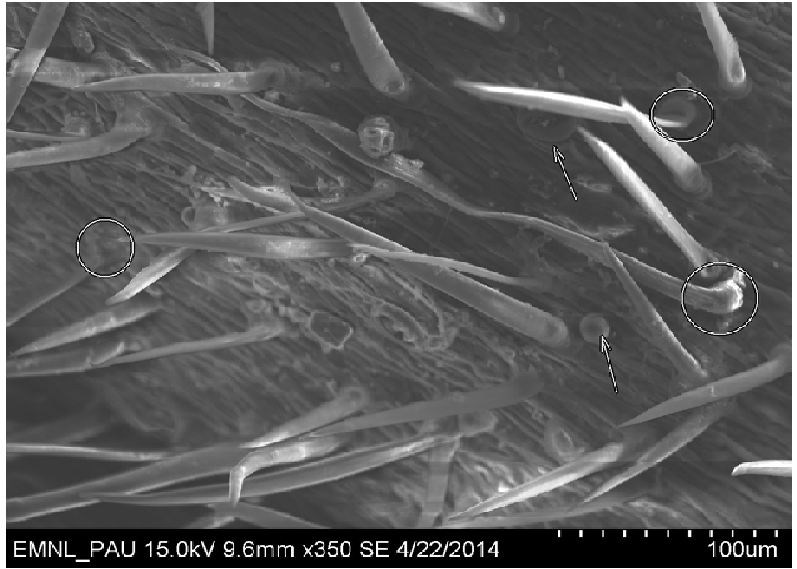

Resistant genotype - AL 1747

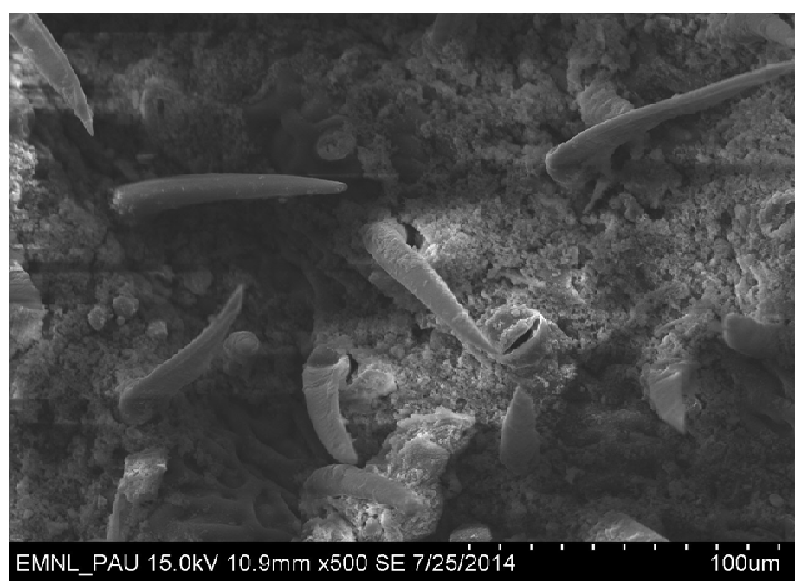

Susceptible genotype - MN 1

Plate 2. Scanning electron micrographs of the pod surface of resistant and susceptible pigeonpea genotypes (a-b) showing trichome density (100um corresponds to $6.5 \mathrm{~cm})$.

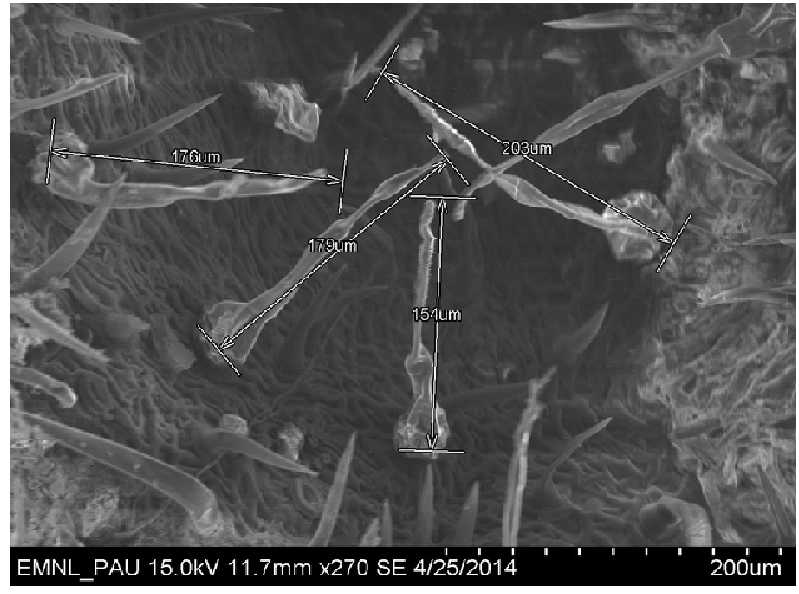

a. Resistant genotype - AL 1747

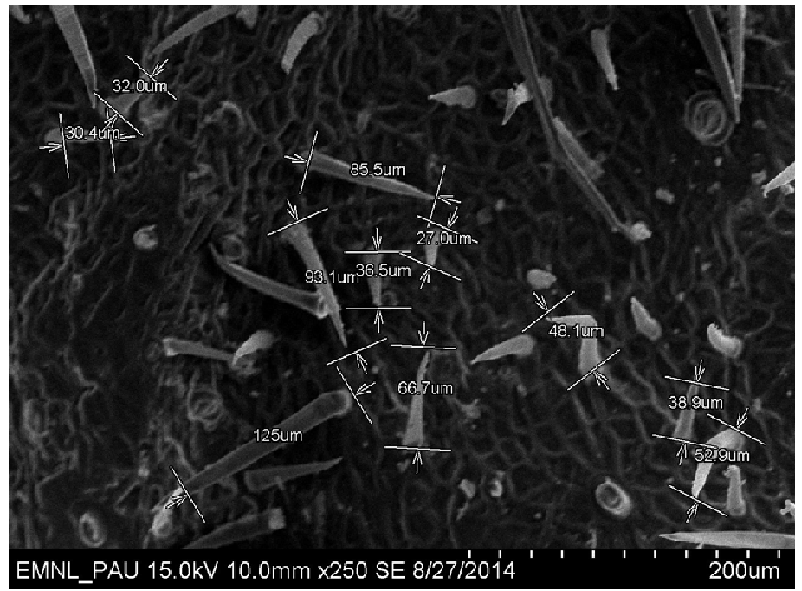

b. Susceptible genotype - MN 1

Plate 3. Scanning electron micrographs of the pod surface of resistant and susceptible pigeonpea genotypes (a-b) showing trichome length $(100 \mu \mathrm{m}$ corresponds to $6.5 \mathrm{~cm})$.

genotypes varied from $71.00-77.66^{\circ}$ and $83-87^{\circ}$, respectively (Table 1$)$. Lowest trichome angle $\left(71^{\circ}\right)$ on leaves was recorded in AL 1735 and highest trichome angle in genotype AL $201\left(77.66^{\circ}\right)$. The differences in the trichome angle on the leaves were, however, nonsignificant. As far as the trichome angle on the pods was concerned, the lowest trichome angle of $83^{\circ}$ was recorded on the pods of genotypes ICPL 98003 and PAU 881, whereas highest trichome angle was observed in $\mathrm{AL} 1747\left(87^{\circ}\right)$. The differences in the trichome angle on the pods were, however non-significant.

On the basis of growth habit, there were marked differences among the various test genotypes of pigeonpea. Genotypes AL 1495, AL 1735, AL 1747, AL 1770, AL 1790, AL 201 and PAU 881 were categorized as indeterminate types, whereas genotypes ICPL 98003, ICPL 20340, MN 1 and AL 15 were categorized as determinate types (Table 2). In the present study, determinate genotype MN 1 (moderately susceptible) recorded significantly highest pod damage (40.61\%), whereas significantly lowest pod damage (7.97\%) as observed in indeterminate genotype AL 1747 (highly resistant). This finding is in accordance with Saxena et al. (1996) and Choudhary et al. (2013), who also reported that determinate pigeonpea genotypes with clustered inflorescence were more susceptible to $M$. vitrata than indeterminate types.

The pod wall thickness of the test genotypes of pigeonpea varied from 60.79-88.26 $\mu \mathrm{m}$ (Table 2). Lowest pod wall thickness $(60.79 \mu \mathrm{m})$ was recorded in AL 15 and highest $(88.26 \mu \mathrm{m})$ in ICPL 20340. However, pod wall thickness was observed to be statistically non-significant among all the genotypes. Data pertaining to pod angle of different test genotypes of pigeonpea ranged from 18.66-65.00 (Table 2). The pod angle was significantly narrow in MN $1\left(18.66^{\circ}\right)$, followed by ICPL $20340\left(20.00^{\circ}\right)$ and AL 15 $\left(23.66^{\circ}\right)$, while it was wider in $\operatorname{AL} 1747\left(65.00^{\circ}\right)$. The genotypes, viz. AL 1735, AL 1770, AL 1495, PAU 881, ICPL 98003, AL 1790 and AL 201 recorded 48.66, 48.33, $43.00,36.33,36.00,34.66$ and $33.66^{\circ}$, respectively. 
Table 2. Growth habit, mean pod wall thickness and pod angle of test genotypes of pigeonpea.

\begin{tabular}{lllll}
\hline S. No. & Genotypes & Growth habit & Pod wall thickness $(\boldsymbol{\mu m})$ & Pod angle $\left(^{\circ}\right)$ \\
\hline 1 & AL 1495 & Indeterminate & 67.55 & $43.00(6.62)$ \\
2 & AL 1735 & Indeterminate & 80.61 & $48.66(7.04)$ \\
3 & AL 1747 & Indeterminate & 74.75 & $65.00(8.11)$ \\
4 & AL 1770 & Indeterminate & 64.13 & $48.33(7.01)$ \\
5 & AL 1790 & Indeterminate & 68.89 & $34.66(5.95)$ \\
6 & ICPL 98003 & Determinate & 72.82 & $36.00(6.07)$ \\
7 & ICPL 20340 & Determinate & 88.26 & $20.00(4.56)$ \\
8 & MN 1 & Determinate & 62.91 & $18.66(4.42)$ \\
9 & AL 15 & Determinate & 60.79 & $23.66(4.94)$ \\
10 & AL 201 & Indeterminate & 75.39 & $33.66(5.87)$ \\
11 & PAU 881 & Indeterminate & 73.85 & $36.33(6.10)$ \\
\hline CD $\mathbf{( p = 0 . 0 5 )}$ & - & NS & $\mathbf{( 0 . 7 1 )}$ \\
\hline
\end{tabular}

Means of three replications; Figures in parentheses are the means of $\sqrt{ } n+1$ transformations; NS: non-significant

Table 3. Correlation studies of different variables on larval weight gain and pod damage due to $M$. vitrata in pigeonpea .

\begin{tabular}{lcc}
\hline Morphological characters & \multicolumn{2}{c}{ Correlation coefficient $(\mathbf{r})$} \\
\cline { 2 - 3 } & Larval weight gain $(\mathbf{m g})$ & Pod damage $(\%)$ \\
\hline Trichome density on leaves $\left(4.6 \mathrm{~cm}^{2}\right)$ & $-0.71^{* *}$ & $-0.75^{* *}$ \\
Trichome density on pods $\left(4.6 \mathrm{~cm}^{2}\right)$ & $-0.69^{* *}$ & $-0.75^{* *}$ \\
Trichome length on leaves $(\mu \mathrm{m})$ & $-0.81^{* *}$ & $-0.87^{* *}$ \\
Trichome length on pods $(\mu \mathrm{m})$ & $-0.81^{* *}$ & $-0.87^{* *}$ \\
Trichome angle on leaves $\left({ }^{\circ}\right)$ & -0.05 & -0.16 \\
Trichome angle on pods $\left({ }^{\circ}\right)$ & 0.06 & 0.11 \\
Pod angle $\left({ }^{\circ}\right)$ & $-0.78^{* *}$ & $-0.83^{* *}$ \\
Pod wall thickness $(\mu \mathrm{m})$ & -0.30 & -0.12 \\
\hline
\end{tabular}

** Significant at $1 \%$ level of significance; Means of three replications

Correlation between morphological characteristics of leaves and pods of test genotypes with larval weight gain and pod damage: The data highlighting the correlation of leaf and pod characteristics of pigeonpea with larval weight gain and per cent pod damage have been presented in Table 3. Significant negative correlation was observed between trichome density on leaves and larval weight gain $(r=-0.71)$ and per cent pod damage $(\mathrm{r}=-0.75)$, indicating that higher the trichome density on leaves, lesser would be the larval weight gain and per cent pod damage. Trichome density on pods showed significant negative correlation with larval weight gain and per cent pod damage $(r=-0.69$ and -0.75 , respectively), indicating that higher the trichome density on pods, lesser would be the larval weight gain and per cent pod damage.

The present result is in accordance with the findings of Halder and Srinivasan (2011) who observed presence of dense trichomes on leaves of resistant cowpea genotype HC-270 while trichome density was low in susceptible genotype GC-9708. A significant negative correlation was observed between trichome density and pod damage. Similar observations were also documented by Halder et al. (2006) who reported that significant negative correlation was obtained between trichome density on pods and pod damage. The data highlighting the correlation between the trichome length on leaves showed significant negative correlation with larval weight gain and per cent pod damage $(r=-0.81$ and 0.87 , respectively) indicating that the more the length of trichomes on leaves the lesser larval weight gain and per cent pod damage. Similarly, the trichome length on pods showed significant negative correlation with larval weight gain and per cent pod damage $(r=-$ 0.81 and -0.87 , respectively) indicating that the more the length of trichomes on pods the lesser would the larval weight gain and per cent pod damage.

In pigeonpea, the trichome density on the upper and lower surfaces of leaf, and length and trichome density on pods were found to be positively correlated with the resistant genotype ICPL 98003 against $M$. vitrata (Sunitha et al., 2008). The length and density of trichomes were more in the resistant genotypes as observed by Jackai and Oghiakhe (1989) who demonstrated that the trichomes were responsible for resistance in wild cowpea TVNu-72 and TVNu-73 to $M$. vitrata as compared to the susceptible variety IT 84 E-124. They reported that the length of trichomes were important in contributing resistance. Oghiakhe et al. (1991b) observed the adverse effects of pubescence in wild and cultivated cowpeas on oviposition, mobility, food consumption and utilization by $M$. vitrata. According 
to Oghiakhe et al. (1991a), the cowpea cultivars IT-82D-716 (susceptible), MRV2-84F (moderately resistant) and TVu-946 (resistant) showed variation in trichome length and density on different plant parts. Correlation studies between physico-chemical parameters of pigeonpea genotypes with larval weight gain and pod damage $(\%)$ by $M$. vitrata under greenhouse conditions revealed that trichome length and density on leaves and trichome length on pods had significantly negative correlation with larval weight gain but trichome density on pod did not exert any significant effect (Sunitha et al., 2008).

The data highlighting the correlation between the trichome angle on leaves showed non-significant and negative correlation with larval weight gain and per cent pod damage ( $r=-0.05$ and -0.16 , respectively). The correlation between the trichome angle on pods also showed non-significant but positive correlation with larval weight gain and per cent pod damage $(\mathrm{r}=$ 0.06 and 0.11 , respectively). However, pod angle showed significant negative correlation with larval weight gain and per cent pod damage $(r=-0.73$ and 0.83 , respectively) indicating that the wider the pod angle, the lesser would be the larval weight gain and per cent pod damage. The present study is in accordance with Halder and Srinivasan (2007) who reported similar findings on urdbean and also found that pod infestation was higher in cultivars that had two or more pods close together at a narrow angle than those cultivars with pods apart. This was probably because larvae were unable to adequately conceal themselves and easily fell prey to parasites, predators and desiccation in genotypes with wider pod angles.

Pod wall thickness showed non-significant and negative correlation with larval weight gain and per cent pod damage ( $r=-0.30$ and -0.12 , respectively). The finding of the present study is in conformity with the previous findings of Halder et al. (2006) who also reported negative correlation between pod wall thickness and pod damage by $M$. vitrata in different cultivars of mungbean.

\section{Conclusion}

The results of the present study have provided critical information on the sources of resistance in pigeonpea towards $M$. vitrata and their associated interactions with crop damage. The results on the percentage pod damage obtained from field and net house studies helped to categorize the genotype AL 1747 as highly resistant, and MN 1 as moderately susceptible to $M$. vitrata. The resistance in AL 1747 could be attributed to certain morphological parameters including pod angle, trichome density and length on leaves and pods which significantly contributed to the resistance of this genotype. It can, therefore be concluded that early maturing pigeonpea genotypes with indeterminate growth habit, higher leaf and pod pubescence with wider pod angles should be preferred for breeding $M$. vitrata tolerant lines. Consequently, these traits need to be incorporated into breeding programmes for resistance to $M$. vitrata with the aim of further improving IPM programmes against this important pest of legumes.

\section{REFERENCES}

Aruna, R., Rao, M., Reddy, L. J., Upadhyaya, H. D. and Sharma, H. C. (2005). Inheritance of trichomes and resistance to pod borer (Helicoverpa armigera) and their association in interspecific crosses between cultivated pigeonpea (Cajanus cajan) and its wild relative C. scarabaeoides. Euphytica 145: 247-257.

Bernays, E. A., Chapman, R. F. and Singer, M. S. (2000). Sensitivity to chemically diverse phagostimulants in a single gustatory neuron of a polyphagous caterpillar. Journal of Comparative Physiology 186: 13-19.

Bozzola, J. J. and Russell, L. D. (1999). Electron Microscopy: Principles and Techniques for Biologists. $2^{\text {nd }}$ Edition, Jones and Bartlett Publishers, Inc. Sudbury, MA, USA, pp. 670 .

Choudhary, A. K., Raje, R. S., Datta, S., Sultana, R. and Ontagodi, T. (2013). Conventional and molecular approaches towards genetic improvement in pigeonpea for insects resistance. American Journal of Plant Sciences, 4: 372-385.

FAO (2005). Agricultural Production Statistics. United Nations.

Halder, J., Srinivasan, S. and Muralikrishna, T. (2006). Role of various biophysical factors on distribution and abundance of to spotted pod borer, Maruca vitrata (Geyer) in mung bean. Annals of Plant Protection Science, 14: 49-51.

Halder, J. and Srinivasan, S. (2007). Biochemical basis of resistance against Maruca vitrata in urdbean. Annals of Plant Protection Science 15: 287-290.

Halder J and Srinivasan S (2011) Varietal screening and role of morphological factors on distribution and abundance of spotted pod borer, Maruca vitrata (Geyer) on cowpea. Annals of Plant Protection Science 19:71-74.

Jackai, L. E. N. and Oghiakhe, S. (1989). Pod wall trichomes and resistance of two wild cowpea, Vigna vexillata accessions to Maruca testulalis (Geyer) (Lepidoptera: Pyralidae) and Clavigralla tomentosicollis (Hemiptera: Coreidae). Bulletin of Entomological Research 79, 595-605.

Karkkainen, K. and Agren, J. (2002). Genetic basis of trichome production in Arabidopsis lyrata. Heredity 136: 219-226.

Kennedy, G. G. (2003). Tomato, pests, parasitoids and predators: tritrophic interactions involving the genus Lycopersicon. Annual Review of Entomology 48: 51-72.

Lam, W. K. F. and Pedigo, L. P. (2001). Effect of trichome density on soybean pod feeding by adult bean leaf beetles (Coleoptera: Chrysomelidae). Journal of Economic Entomology 94: 1459-1463.

Muigai, S. G., Schuster, D. J., Scott, J. W., Basset, M. J. and McAuslane, H. J. (2002). Mechanisms of resistance in Lycopersicon germplasm to the whitefly Bemisia argentofoli. Phytoparasitica 30: 347-360.

Oghiakhe S, Jackai L E N and Makanjuola W A (1991a) Anatomical parameters of cowpea Vigna unguiculata (L.) Walp. stem and pod wall resistance to the legume pod borer Maruca testulalis (Geyer) (Lepidoptera : Pyralidae). Insect Science and its Application 12: 171-176.

Oghiakhe, S. Jackai, L. E. N. and Makanjuola, W. A. (1991b). Cowpea plant architecture in relation to infes- 
tation and damage by the legume pod borer, Maruca testulalis (Geyer) (Lepidoptera: Pyralidae): effect of canopy structure and pod position. Insect Science and its Application 12: 193-199.

Ranga Rao, G. V., Ashwini Kumari, P. R., Rameswar Rao, V. and Reddy, Y. V. R. (2007). Evaluation of spinosad and indoxacarb for the management of legume pod borer, $M a$ ruca vitrata. Journal of Food Legumes 20:126-27.

Saxena, K. B., Lateef, S. S., Ariyaratne, H. P., Fenseka, H. H. D. and Dharmasena, C. M. D. (1996). Maruca testulalis damage in determinate and indeterminate lines of pigeonpea. International Pigeonpea Newsletter 3: 91-93.

Saxena, K. B., Chandrasena, G. D. S. N., Hettiarachchi, K., Iqbal, Y. B., Fonseka, H. H. D. and Jayasekera, S. J. B. A. (2002). Evaluation of pigeonpea accessions and selected lines for reaction to Maruca. Crop Science 42: 615-618.

Sharma, H. C. and Franzmann, B. A. (2000). Biology of the legume pod borer, Maruca vitrata (Fabricius) and its damage to pigeonpea and adzuki bean. Insect Science and its Application 20: 99-108.

Sharma, H. C., Sujana, E. G. and Manohar Rao, E. D. (2009). Morphological and chemical components of resistance to pod borer, Helicoverpa armigera in wild relatives of pigeonpea. Arthropod-Plant Interactions 3: 151-161.

Simmons, A. T. and Geoff, M. G. (2004). Trichome-based host plant resistance of Lycopersicon species and the biocontrol agent Mallada signata: Are they compatible? Entomologia Experimentalis et Applicata 113: 95-101.

Simmons, A. T., Geoff, M. G., Mc Granth, D., Nicol, M. M. and Peter, H. I. (2004). Entrapment of Helicoverpa armigera (Hubner) (Lepidoptera: Noctuidae) on glandular trichomes of Lycopersicon species. Australian Journal of Entomology 43: 196-200.

Sunitha, V., Ranga Rao, G. V., Vijaya Lakshmi, K., Saxena, K. B., Rameshwar Rao, V. and Reddy, Y. V. R. (2008). Morphological and biochemical factors associated with resistance to Maruca vitrata (Lepidoptera: Pyralidae) in short duration pigeonpea. International Journal of Tropical Insect Science 28:45-52.

Valverde, P. L., Fornoni, J. and Nunez-Farfan, J. (2001). Defensive role of leaf trichomes in resistance to herbivorous insects in Datura stramonium. Journal of Evolutionary Biology 14: 424-432. 